\title{
a ideia
}

Wagner Lacerda*
03:12

Nossa, já é isso tudo... Acho que vou levantar para fazer um cafe... Para que fur ter a droga da ideia.

03.26

Ah não. Outra vez esse filme... Off Preciso Ah năo. Outra vez esse filme... Off Preciso ra que isso dê em alguma coisa. Quem sabe o Guiness? Quem é que tinha esse troço mesmo? Acho que era 0 tio Paulo... Eu me lembro de um cara que comeu sessenta e dois amendoins em um minuto - mais de um por segundo! Ou quase isso... Acho que era isso...

O dia seguinte 
A atendente não tinha um ar muito simpático. começava a acontecer algo macabro. Três da manhã

- Bom dia!

- Bom dia.

Como é que eu faço para pegar livro?

Você tem ficha?

-Não. Precisa de quê para fazer uma?

RG, CPF e comprovante de residência.

(CPF para pegar livro?)

Aguarde um minuto.

$\cdots$

(Bem mais de um minuto...)

- Pronto. Qual livro você quer?

Todos.

Como assim todos?

- Todos os que você tiver aí, claro!

03:55

Acho que cochilei... Cadê o celular?

...

Eu me lembro de um filme que tinha uma história muito 78 louca. Sempre que o relógio mostrava três da manhã era a hora do demônio Por quê? Seilá.

Ainda o dia seguinte

Mas, é contra as regras!

Que regras?

- Você... Aguarde um minuto.

(Muito mais de um minuto...)

- Seria se eu te pedisse um vidro de xarope.

04:34

É. Eu sei. Vai parecer um tanto estranho. Ah! Mas é uma ideia e tanto! Duvido que alguém já tenha

$$
\text { On }
$$

Australiana adota uma lhama... Morto consegue uma vaga no parlamento búlgaro...

off

Não adianta. Não consigo mais parar de pen sar nisso. Vai amanhecer logo... Como eu vou começar? Tem de ter um critério. Qual? Por ano? Por gênero? Por

On.
- É alguma brincadeira?
Sua consulta localizou aproximadamente 62.200 .00 resultados para livros.

-..

Off

Qualquer dia... Antes ou depois...

Screen Test: Salvador Dali by Andy Warhol (1966)

$05: 33$

Como demora para amanhecer no inverno.

Rambo?!?!

...

Cadê o controle?

Alelvia! Alelvia!...

off

Acabou o café... Já sei! Seguindo uma linha cronológica... Mas, será que revistas e jornais contam? Quando editaram a primeira revista? E o primeiro jornal?

Deixa disso... Vai complicar demais. Só vai valer livro... Como eu vou descobrir o que publicaram na Polônia?. E em Lietchenstein?
On

Sua consulta localizou aproximadamente 48 re sultados para livros em Lietchenstein.

Tem um artista chamado Roy Lietchenstein... Parece que é desenhista... Não escreveu nada...

\section{off}

$$
\text { A padaria abriu. Que neblinão... }
$$

Um pouco depois

Já sei! Agora eu tenho certeza! VOU LER TU DO OUE EXISTE! E qual vai ser a regra? NENHUMA! critério é não ter critério. Entrar em sebo, biblioteanotando. Anoto os nomes Compro um caderno e vou onde e quando eu consegui o livro. Assim não vai dar confusão. Começo hoje sem falta.

06:49

Eu tenho de conseguir os endereços de todos os sebos, livrarias e bibliotecas da cidade... Entro lá e peço TUDO Como eu vou fazer com o que eu não achar por aqui?

07:13

Vou descansar um pouco... Depois do almoço, eu penso melhor em tudo... Acho que vou lá na padaria tomar outro café... Saco... Que frio 
O debate que se segue, sobre o conto "A ideia", de Wagner Lacerda, foi realizado por e-mail no período $d$ 18 a 02 de maio de 2011, pelas alunas de pós-graduaçãa elho*.

Carolina Messias: Realmente são muito raras as oportunidades de tar da discussão de um conto contemporâneo - o que oferece a este convite ao diálogo um tom de desafio surpresa.

Laura Penna Alves: $O$ conto traz de modo interessante marcações de tempo como a sinalização das horas (dispostas quase como um cabeçalho de diário), as reticências e o dispositivo on/off. As horas aparecem de modo a respeitar a verossimilhança temporal e estão na ordem cronologica indicando que o que se passa é de madrugada. Na verdade, elas funcionam mais como um recurso grafico, dado que eles não trazem um sentido, alem deste evidente, para a narrativa. As reticencias, contudo, são um recurso cujo emprego é mais interessante porque indicam um tempo fora desse tempo cronológico e que marca uma temporalidade a ser criaprolo que seriam incarvalos de uma figuraçao de um o recurso on loff talvez seja mais propriamente criativo. Ele anuncia a mudança de vozes enunciativas: fluxo de pensamento do narrador e programas de televisão. Até aí isso seria um emprego evidente se não tivéssemos um último off que se refere tanto a televisão como ao narrador. Ambos desligam e o conto acaba. Ora essa junção de vozes que acontece no final do conto não tem força, contudo, para ressignificar o conto inteiro. Isso porque, ao longo deste essa divisão é feita de modo previsível e a "grande ideia" não parece ter um sentido enriquecido pelo que poderia ter se transformado num homem-tv ou numa tv-homem... Não sei... acho qu esse e um dos problemas do conto, o que vocês acham?

* Ana Amelia Coelho é mestranda do Programa de Estudos Linguísticos Literários e Tradutologicos do Departamento de Letras Modernas (DLM) USP. Contato: anameliacoelho@gmai.com. Carolina Messias é mestranda

80 yahoo com br Laura Pena Alves é editora da revista opinin̈es
A marcação do tempo, como foi destacado pela Laura, é um recurso interessante e que poderia ser ainda mais explorado no conto "A ideia", justamente para deixa de ser um mero recurso gráfico e passar a oferecer uma carga significativa no alinhavamento temático-forma do conto. A precisáo das horas indicadas por esse re"Qualquer dia... Antes ou depois"; e "Um pouco decronológico vivido pelo personagem e indicam una mudança de plano temporal dúbia pois não sabemos se trata-se de um flashforward, isto é, a apresentação de um momento futuro ao que o personagem está vivendo, ou da figuração do fluxo de pensamento ou ate de um sonho do personagem. Esse jogo entre tempo vivido e tempo experimentado também é corroborado pelo uso das reticências e do on/off, como você apontou, Laura. Este último recurso, que marca a mudança de tempo e de voz do conto, não parece estar ligado apenas a programas de televisão e sim à presença de uma máquina, no sentido mais genérico... A dúvida sobre a que se refere o on/off surgiu por conta das seguintes frases: "Sua consulta localizou aproximadamente 62.200.00 resultados para livros" e "Sua consulta localizou aproximadamente 48 resultados para livros em Lietchenstein (sic)", que parecem mais próximas de um site (ou ferramenta) de busca do que de um programa quem acionaria esse "botão" na narrativa, pois, mut tas vezes, o próprio narrador parece ser "desligado" ou logio digital que fica na cabeceira de cada pensamento do narrador-personagem é rompida em quatro momentos, na estrutura do conto, por expressões inde"Ounas. "O dia seguinte", "Ainda o dia seguinte" "ligado" de sua própria voz, tornando-se mais uma voz nesse universo de imprecisão da madrugada. Comecei estabelecer essa relação entre homem e máquina a partir das referências ao filme de Andy Warhol e ao trabalho de Roy Lichtenstein, artistas do Pop art que pretendiam denunciar em seus trabalhos a massificação da cultura capitalista. Caberia essa aproximação? Nesse sentido, a ideia de junção de vozes que acabariam "desligadas" (off) é bastante interessante, mas perde a força, acredito, por não apresentar nenhuma
com a "ideia" que pretende sustentar o conto.

Aliás, num primeiro momento, a "ideia" anunciada como centro do conto, acaba ficando à margem, devido a falta de conexão com os demais elementos (tempo, espaço, vozes presentes na narrativa). O que poderia ser uma provocaçăo (a empreitada de ler tudo o que existe sem estabelecer um criteri
preender o leitor, vocês não acham?

LPA: Puxa Carol, legal você ter falado dessa outra mar("O te" etc.) porque também tinha pensado nela como um elemento desestabilizador de um verossímil evidente no que toca à percepção tanto do tempo como do espaço. Contudo, se nos perdemos no dialogo com a atendente, introduzido após "O dia seguinte", logo depois voltamos ao verossímil banal, presente num clichê muito querido dos chamados "filmes para a TV": "Acho que cochilei.... Cadê o celular". Bom, sobre o on e o off não se referirem ao programa de televisão e verdade. O caso é que eu redigi aquele parágrafo em cima das minhas anotaçōes e acabei usando o termo televisão como um termo genérico. Peço desculpas adiantadas ao autor que me lerá. Realmente, além do on temos 0 recurso ao itálico para marcar sentenças que praticamente reproduzem o ritmo e os conteúdos que circujornais. esse sentido, quando você diz que esse mecanismo onloff está ligado a uma ideia geral de "máquina", pede ser pensada a partir dessa metáfora da máquina al como antigamente, pois as pessoas interagem odos ali são potencialmente criadores de um espaço. Afinal, o que seria essa ideia se não a possibilidade-impossivel de realizar-se google? É engraçado né? No poema "Tabacaria" Álvaro de Campos dizia: "Gênio? Neste momento. / Cem mil cérebros se concebem em soho gênios como eu"1. Será que o que temos agora são "sonhos Google"? Não é esse o caso deste conto, que "sem o mérito de tentar problematizar a angústia da infinitude de informaçōes e a ausência de critérios.

Contudo, apesar de trazer essa tensão à tona, a linguaem empregada não é eficaz do ponto de vista perfor mativo. Assim, o conto começa: "3:12 Nossa, já isso . pria Meschonnic que se preocupa em soar o menos distinta possivel daquele ritmo já compartilhado por muitos falantes. Assim nesse caso, temos esse tempo da interjeição "Nossa!", seguida de uma constatação. Ora, este narrador-personagem segue sucessivamente pensando em lugares comuns e empregando tempos rítmicos já automatizados. Assim, temos a representação de um fluxo de pensamento que segue de modo comportado, sem nada que saia do que seria de "bom om ser pensado". A repetição desses tempos e dos assuntos, apesar do surgimento da grande ideia, acaba or não permitir a presença de sentidos mais amplos propriamente criticos. Nesse sentido, e interessante pensar no que você falou da pop Art porque daria para (azer um paralelo nesse sentido e pensar a eficácia desa linguagem, na maioria das vezes reprodutiva, para

Assim, o conto talvez seja bem representativo de um momento no qual parece que o tempoé escasso (talvez 
porque o tempo da solidão o seja) e o espaço, agora tambèm vifual, traz uma infinitude de possibilidad contraditas, de modo radical, por um corpo preso a
uma cadeira, um apartamento, um trajeto casa-padaria etc. e um olhar para o mundo totalmente desistoricizado e pouco critico. O interessante da grande ideia do é tornada possível por uma representaçăa pouco crítica dessa outra relação com o conhecimento que a internet parece engendrar. Nesse sentido, o argumento do conto e rico, mas pelas razões levantadas acima ele não se desenvolve de modo mais proficuo. Disse que o útimo off poderia ter se transformado num homem-T pensando melhor, ele já está presente no conto e talvez seja justamente esse o problema. Ele tem um corpo uma solidão que ligamos a uma representação geral d relação com a TV. Contudo, a internet, que faz parte
como tema, está no horizonte, mas não tem ainda um como tema, está no horizonte, mas não tem ainda um corpo e uma perspectiva própria. Esse corpo é passivo da internet, como se assistisse a um programa Na ver dade ler tudo é quase uma nãoidei, nesse sentido, pois não há propriamente a invenção de nada.

Ana Amélia Coelho: Entro no debate já vendo questões bem desenvolvidas por vocês duas $\mathrm{e}$, o que é intere sante, bem diversas daquelas que eu tenho em mente. $\mathrm{O}$ que me pareceu, antes de tudo, fundamental nesse escrito, é seu caráter lacunar. Há uma série de espaços vazios e horas pouco definidas do dia: o espaço em que a pessoa que fala espera amanhecer, espera que algo aconteça. Ao mesmo tempo, logo nas primeiras linh a "ideia" ja aconteceu - e o efeito é decepcionante: "a droga da ideia", que vai de qualquer forma impulsion todo o curto conto.

Como e para quem fala essa voz? A imagem que constrina pente foila de alguem quetemaqueles pequenos

82 lor do momento ideias passageiras, frágeis promessas para projetos futuros, feitas de pequenos pedaços do cotidiano. Sem preparação, sem rodeios, esse conto lavra que se dirige a um eu do futuro não muito distante, numa fita cassete que também pode ser regravada - podemos passar por cima, apagar, regravar; o tempo o esquecimento também podem destruir esse registro efêmero. É uma palavra sem grandes pretensões, que guarda ideias mirabolantes, capazes de mudar tudo, porque o que se busca, já se sabe desde o princípio, impossivel.

Com base nesse impossivel a voz se mistura a outras, traz diálogos do dia-a-dia, em que claramente a voz se diferencia das outras, no tom de desafio (não se pode emprestar todos os livros, a burocracia é grande, um minuto náo dura real disente um minuto). Essa voz quer se distanciar de tudo o que a rodeia, quer estar acordasi mesma os sus dorm, prefere fechar-se em no problema do conto: ele não se divide com o leitor. Quem nunca desejou ler todos os livros, ou se confrontou com esse grande abismo entre a nossa capacidade de ler e memorizar e o volume de todo o con cimento humano? Como assistir a todos os canais de televisão ao mesmo tempo? Seria possivel registrar cada peque no instante em nossa memória, como se fossem pequenos tesouros pessoais? E como se faz para conhece as terras mais longínquas, de nomes estranhos?

E nisso tudo, como pode o Google abarcar tudo o que conhecemos? Será mesmo que ele consegue fazer isso? E frente o poder descomunal dos acervos das bibliotecas, dos resultados dos mecanismos de busca que o texto tenta desafiar, com uma "droga de ideia". Uma pequena ideia, em momentos marcados pelo relógio,

Nesse sentido, o conto lembra muito escritos de adolescência; imaginei que eu mesma poderia encontrar algo assim num caderno perdido dos tempos do colegial, a mente divagando no meio de uma aula chata, ou no tédio de uma tarde em que se tem pouca coisa para fazer.

Sim, como já foi assinalado por vocês duas, o conto todo não trabalha com propriedade essa grande força motriz (e podemos ai pensar em todas as máquinas que evocamos: internet, televisão, gravador) para ir mais longe nessa impossibilidade, nesse desejo inalcançável de ler tudo, conhecer tudo desde o princípio (a primeira revista, o primeiro jornal). Ainda assim, ele continua indo e vindo na leitura e nos coloca o desafio de falar criticamente, trazer discursos, ocupar os espaços vazios que ele deixa.

CM: Mais dificil do que preencher solitariamente os vazios que o conto apresenta para mim, leitora, é ocupar os espaços das ideias que vocês estáo apontando neste tários de vocês, volto ao conto no momento em que 0 narrador-personagem julga sua ideia como estranha original: "É. Eu sei. Vai parecer um tanto estranho. Ah! Mas é uma ideia e tanto! Duvido que alguém já tenha pensado nisso. Será que o Jô vai querer me entrevistar? $\mathrm{On}^{\prime \prime}$. O tom apresentado nesse trecho, marcado pela oralidade das expressões e pelas frases curtas com lugares-comuns, parece mesmo indicar que a ideia não sairá da promessa e sera apenas um registro efêmero, como a Ana disse, de um desejo de sair desse cotidiano comum. Apesar disso, năo sei se essa voz quer se distanciar do mundo em que vive, já que o primeiro registro do narrador apos notar a possibilidade de ter tido uma ideia original, é a pergunta se ela despertará o interesse na midia: "Sera que o Jô vai querer me entrevistar?" Não adianta. Ele não consegue sair do lugarcomum. Sua empreitada causaria o mesmo interesse thama e do morto que se tornou político? Além disso acredito que onarador estaria tentando se distanciar de tudo que o rodeia se justificasse sua ideia, isto é, indicasse um motivo legítimo para ler tudo o que existe, porm, ele se pergunta: "Será lque vai da quer?? Tomara que isso dê em alguma coisa. Quem sabe Guinness?" A razão dessa empreitada seria ocupar um espaço na página dessa enciclopédia de recordes ao lado "cara que comeu sessenta e dois amendoins em m minuto"? Parece que o narrador-personagem não quer se distanciar, mas se integrar nesse conjunto de vozes que surgem no conto.

Neste ponto, não há como não estabelecer uma breve elação entre a ideia do narrador-personagem e a em preitada de Flaubert e de seus personagens Bouvard Pécuchet (1881). Tanto o criador quanto as criaturas sentiram essa angústia da infinitude de informações,

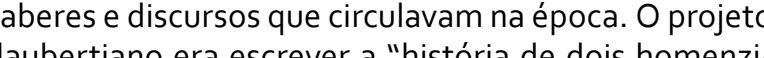
laubertiano era escrever a "historia de dois homenzihos que "opiam uma espécie de enciclopédia critica de Genettes em 1872. Para isso teve que ler mutos II ros sobre assuntos que desconhecia: química, agriculura, história, etc. Por sua vez, os personagens não só copiam os livros, como procuram colocar suas teoria em prática, seguindo o mesmo critério do narrador-personagem de "A ideia": "O critério é não ter critério." Resultado? Flaubert morreu antes de terminar história dos copistas. Maupassant, inclusive, escreveu após a morte de Flaubert: "Um livro como este devora m homem, pois nossas forças são limitadas e nosso esforço não pode ser infinito".'

Trago essa referência do século XIX para mostrar o quanto essa questão é, ao mesmo tempo, antiga tual. Se o tempo ja era escasso, naquela época, para o sucesso dessa ideia de ler tudo que existe, imagine hoje, com a velocidade de transmissão das informa por isso, um dos critérios escolhidos pelo narrador -personagem é a pesquisa somente de livros, cujo 
texto aparentemente é menos fugaz que o de uma noticia de jornal ou revista. Hoje a Internet, sobretudo de um infinito apreensivel, da possibilidade de decifra o enigma da totalidade do conhecimento. Tanto que o narrador parece consultar esse site de busca para responder às questões que são impostas por sua grand ideia: "(...) Como eu vou começar? Tem de ter um critério. Qual? Por ano? Por gênero? Por autor? Por país? on. / Sua consulta localizou aproximadamente 62.200.00 resultados para livros." e "(...) Como eu vou descobri o que publicaram na Polônia? E em Lietchenstein? On / Sua consulta localizou aproximadamente 48 resultados para livros em Lietchenstein." O número de result dos diminui, mas não o problema do narrador-personagem, que descobre um novo dado de sua busca a partir Lietchenstein (sic)... Parece que é desenhista... Não esLietchenstein (

Esse novo elemento parece apontar para a angústia Ese navo la nhecimento em rede, presente num espaco virtual en que os discursos interagem livremente. $E$ interessante pensar na proposta de ler tudo que existe como uma não-ideia, como a Laura levantou, tanto por não haver solução possivel ou invenção no que o narrador se propõe, como no adiamento da reflexão da ideia que o narrador deixa para depois do almoço.

Acho que deixei várias pontas soltas neste comentário, mas não quero estendê-lo demais. Preciso de un pouco mais de tempo para processar tudo o que vocés discutiram.

LPA: Ana, essa ideia de vazios a serem preenchidos do Iser não seria algo mais relativo a fenomenologia da le cunar

84 que, se não me engano, olser chamou de esquema. $\mathrm{Na}$ verdade é difícil pra mim pensar o texto a partir disso. De qualquer forma, concordo que ele tem o mérito $d$ mobilizar um imaginário coletivo que ele tenta desafiar. Contudo, quando o li o conto, essa imagem do gravador não me veio à cabeça Na verdade a primeira coisa que pensei foi: "Nossa, até o que chamamos de fluxo de consciência virou um gênero padronizado!" Esses procedimentos que trazem o ambiente doméstico e intercalação de pensamentos banais com uma ou outra "sacada" é realmente muito comum. No caso do conto isso não seria um problema porque o narrador, teoricamente poderia garantir um ponto de vista critico nos termos em que o Schwarz ou Pasta falam de Bràs Cubas. Inclusive, a grande ideia me lembrou o emplasto Brás Cubas. Contudo, o efelto da ironia ficou pouco eficaz. Então somos avisado de que essa droga de ideia e anunciada em uma linguagem que realmente soa adolescente: "Pra que fui ter a droga de ideia. Saco.". Naria in conto disso que poderia serum ponto de vista

Sobre o que a Carol falou do adiamento da ideia para depois do al Caço, real dente, a sensação que temos é de "eterno retorno", de que aquilo é um eterno presente. Nesse sentido, essa talvez fosse uma diferença importante de nosso tempo em relação ao século XIX. Lá vimos o surgimento de uma cultura enciclopédica que alimentava o sonho fáustico de conhecimento tota do mundo. Hoje, parece năo haver mais interesse pela "máquina do mundo e o importante não e a produção ou o conhecimento de algo, mas o que poderiamos chamar de "experienclia espetacular. Qual a diferenç̧ entre comer muitos amendoins e ler muitos livros? Nenhuma porque a finalidade é a mesma, ser espetáculo. É legal o conto nos permitir pensar isso.

AAC: Quando falei em escrita lacunar, não pensei na teAria de Iser, mas quis trazer mesmo a imagem de lacun a voz

A primeira frase é a constatação da passagem rápida do tempo, sobre a qual não se tem controle: "iá é tudo isso..." - o que o fez perder a noção das horas, justamente se o que temos em seauida são momentos pontuados pelo relógio? Terá sido justamente "a ideia"? No meio do texto, um corte no tempo para qualquer outra direção, "qualquer dia", "antes ou depois". O texto termina tambèm sem muitas grandes perspectivas, com mais pequenas reclamações: de novo "saco", "que frio".

No que diz respeito à marcação do tempo, que figura esse recurso teria no andamento da leitura? Por isso a mim me pareceu mais que essa marcação seria da ordem de uma máquina, daí a imagem que me fiz de um gravador, que, admito,
onde se apoiar no texto. Assim, é possível assinalar, como a Laura já comentou, - uso pouco critico de recursos narrativos, sem que se aproveite a sua potencialidade. A ideia é frustrada logo presente.

Essa voz, reclamona em tom adolescente, busca distanciar-se ou integrar-se a outras? Tanto uma coisa como outra, sob pontos de vista distintos. Concordo com você, Carol, quando ele quer integrar-se à lista de outros feitos extraordinários ou insolitos, como os elencados no Guinness. Ao mesmo em todo feito desse tipo deve funcionar uma vontade de diferenciar-se de uma grande massa de acontecimentos que não rendem para um programa de entrevistas.

CM: Estava bolando ideias para o meu próximo comen- espaço de tempo. A gente vai levantando questões que são difíceis e merecem uma análise mais cuidadosa. 0 o comentário da Laura, inclusive, me fez retomar texto "Algumas questões sobre o conto", do Corzar... gostaria de ler com mais calma esse texto para vamos fazer um intervalo, me senti à vontade para sugerir alguns pontos que podem ser interessantes para nossa discussão:

Por que a escolha do gênero conto para tratar dessa emática?

Por que a brevidade do conto (me) incomoda?

Que detalhes o autor poderia trabalhar mais a fim $\mathrm{d}$ tos tenham maior carga significativa ofereçam maior carga significativa ao conto.

Este é um conto significativo? Refletir sobre esta afirac̃o de Júlio Cortázar retirada do texto "Alguns aspectos do conto" (1974):

Um conto é significativo quando quebra seus próprios limites com essa explosão de energia espiritual que ilumina bruscamente algo que vai muito além da pequena e às vezes miserável história que conta (...) o tempo e o espaço do conto têm de estar como que condensados, submetidos a uma alta pressão espiritual e formal para provocar essa "abertura"

: Ana, concordo com seu comentário sobre a imaem da lacuna no texto. Na verdade, lendo seu comentário de ontem, entendi que o que você apontava como "caráter lacunar" estaria ligado não apenas aos vazios do texto, mas à estrutura fragmentária, que ãa se desenrola até cosfecho para dar luga qual a lução ou à crise). Dialogando com as formas modernas 
do conto, o narrador-personagem de "A ideia" procu ra construir no leitor a sensação de impossibilidade questão do tempo, que já discutimos, como pelas re ferências a discursos de outras mídias, pelo uso dos botôes on/off e pela repetiçãa. Nesse sentido, li esse "fluxo de pensamento padronizado", destacado no último comentário da Laura, como mais um recurso que pretende dialogar com essas formas modernas: a repetição de lugares-comuns, frases e lembrança que poderiam ser de qualquer insone na madrugada. Assim, não consegui ouvir "essa voz adolescente" que vocês comentaram, no conto, pois não identifiquei nenhuma expressão caracteristica da linguagem adolescente. Ao meu ver, "droga" e "que saco" são expressões bastante neutras em relação à faixa etári .

Achei interessante a relação entre a ideia de ler todo não podem se concretizar. Talvez a primeira nã tenha a forca e a ironia da segunda por não apresentar uma função, mesmo que absurda, como a de criar algo que cure a melancolia humana. Por esse motivo, a ideia conto se torna vazia, sem intensidade.

Laura, como seriam esses "elementos autocríticos" que você citou? Os recursos formais utilizados no conto, mesmo que incipientes, não podem ser considerados críticos em relação ao gênero conto?

LPA: É interessante como cada uma, no final das contas, entendeu o termo "adolescente" de um jeito diferente. Ao fim e ao cabo realmente a Carol está certa em sua desconfiança. Se pensarmos bem, alguém poderí ter dito, por exemplo, coloquial. Talvez a palavra tenha surgido por conta de personagens como Fréderic Moresante do que associaçõ qua que podem ser injustas com

86 o conto, o seria pensar procedimentos concretos (como a extensão do conto e as cargas significativas que faCarol) que poderiam intervir mais pontualmente no que seria um processo de escrita futuro deste conto, co so fo um "impensado", algo que criamos partir dele e em nome do que nele vemos como potenauto-críticos não falei em randõa falei em elementos próprio ponto de vista narrativo. Em Memórias Póstumas de Brás Cubas temos certa distância entre o nom Brás Cubas que narra e o nome Brás Cubas que é narrado. A ironia também é auto-irônica. No caso do conto parece que há uma junção dos nomes de modo que o "nome narrado" (aqui ausente no sentido literal) se leva a serio, pois seria seria a "suposta "idelidade" na figuraçăo de um fluxo de pensamento "comum", "mediano" "padrão". Isso seria outro elemento que sufocaria os elementos criticos que vimos no conto. Nesse sentido, não teria nada a propor de concreto para definir esse tem a partir de um contexto textual constituído o má ximo que poderia fazer, e aqui me esforcei para tal, sugerir reflexões e experimentos.

Nesse sentido, achei muito legal as sugestões de reflexão da Carol. Isso porque a discussão estava indo pra um lado que era interessante, mas talvez não fosse muito útil para o autor. Aliás, estou meio arrependida de ter falado que o fluxo de consciência era padronizado. Na verdade, não poderia falar em padrão levianamente, sem de fato investigá-lo... De qualquer forma, quis dizer que o fluxo de consciência, tal como esta neste conto, era um contraponto dessas formas eno emplacam porque ele tem o mesmo tempo rítmico do dialogo com a vendedora, que teoricamente introduziria a indeterminaçáo no tempo e no espaço com "O dia seguinte". Esse ritmo só se altera um pouco com temporalidades frásicas e textuais permitisse cons truir imagens não necessariamente dentro dos limites de um verossímil que respeita o decoro no que toca o ritmo e o modo como ele mobiliza o nosso imaginário independente do qual simpático somos ao tema.

desta forma que, por exemplo, pensar a extensão do conto é realmente interessante. Compartilho aliás, um pensamento absurdo. Pensei que o escritor poderia ter determinado antes o tamanho do conto e só depois disso o teria escrito tendo em mente esse limite. Este completo absurdo me fez lembrar que os contos curtos estão em voga e, há algum tempo atras, lançaram ate o mini-conto por mensagem de celular. Ora, e se estivéssemos todos, não só os especialista da universidade, sob uma especie de "tabu da extensão do objeto"?. Então, mesmo quando pegamos um conto como esse, que claramente ambiciona mobilizar âmbitos complexos do imaginário comum, vemos que, tirando uma tímida tentativa, está bem amarrao numa narrativa breve que teria de ser muito mais Carol para "ma feito pretendido. Vamosa um exem plo concreto de algo que poderia aumentar essa carga e que toca à verossimilhança pretendida. Na passagem "Será que o tô vai querer me entrevistar?" temos "que apontaria como um "verossímil evidente" Com "evidente" queremos dizer que o problema não é o narrador pensar que quer ir no Jô, mas que o modo como faz isso é problemático. Vejamos que com isso a preocupação era criar um efeito de mediania quase estatistico, ainda que revele, agora no detalhe, mais um momento de sua "constrangedora fausticidade, se poderíamos dizer assim.. Contudo, querer ir no Jô não e so uma ocorrencia, mas uma meta, faz parte do objetivo e do sentido dessa "cultura-guiness", no qual a existência depende de todo tipo de visibilidade publica. Aqui, no entanto, isso aparece como um pensamento cuja linguagem não nos remete a senJô é um elemento entre outros e não vemos, nesse pensamento banal, nada que traga a angústia do anonimato ou ironize banalidade do pensamento (o que seria um elemento auto-crítico). Enfim, poderia quver aqui recursos de todo tipo que enriquecessem complexificassem o sentido desse desejo.

M: Tenho pensado muito em alguns elementos que the do aqui e ali em nossa discussão: significação, intensidade (tensão) e brevidade. Nos últimos dias, retome o texto "Alguns aspectos do conto", de Júlio Cortázar (1974), para pensar nessas questôes, pois ele apresenta (1) propó a trocar ideias a respeito do conto (mesmo Ue nos estejamos tratando de um conto especifico, onto de vista critico e acadêmico, e Cortazarar do gênero conto e da forma como escreve, sob o olhar do (ico e do escritor). Uma das afirmaçoes presentes nesse texto insiste em instigar minhas ideias quando

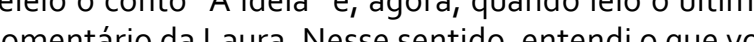
ce apontou como elementos autocríticos e concordo com os experimentos sugeridos por você a coutor: de fato, seria interessante exercitar outras temporalidades frásicas e textuais que "explodissem" os limites do argumento do conto. Paralelamente a isso, penso que guns elementos que se apresentam quase como acessórios, os detalhes, deveriam ser "costurados" no conto de forma a produzir uma rede tensional, por exem plo, o que a Laura falou sobre o pensamento banal de ser entrevistado pelo Jo, ou a indicação das horas que a parecem nos relogios que marcam o tempo da narraiva, dos pensamentos. Esse horario não poderia estar gado a "hora do demónio" do filme que o narrador personagem lembrou? Como o autor poderia trabahar esse demônio como imagem e forma dos próprios ensamentos dele, sobretudo, como imagem da ideía angustiante de ler todos os livros que existem? Talvez ietchtenstein, comentada anteriormente) e o Surrealismo (referência a Salvador Dali, além do ambiente 
soturno, na madrugada, frio e neblina) pudessem ser mais intensificadas nesse sentido, mas isso é apenas portante é refletir sobre os detalhes que podem ser ainda mais enriquecidos e complexificados - eu diria sobretudo na primeira frase às 03:12

A isso está ligada a questão da brevidade do conto tou falando do número de páginas ou de caracteres pois isso não torna o conto melhor ou pior, mas justamente dessa sensação de falta de densidade de a guns recursos formais e visuais. Nesse sentido, ach interessante a Laura ter pensado no autor estabelecendo uma restrição espacial para seu conto, afina a ideia é um lampejo, um "rasgo de sentimento que pode ser intenso mas é de curta duração" (definição do Houaiss, achei tăo bonita que não consegui defi-

Gosto de pensar no conto como um "sequestro momentâneo do leitor", como define Cortázar, pois essa imagem aponta para a inpofisan a dos elementos por meio da tensão entre os elementos formais e expressivos.

AAC: Concordo com a coloquialidade da linguagem com a falta de apuro e trabalho formal que desse mais força expressiva e autocritica ao texto. No meu caso a "adolescência" a que me referi logo de inicio não faria parte necessariamente na narração (mesmo que eu mesma depois, junto com a Laura, tenha feito a associação à adolescencia e às reclamações recorrentes). Pensei antes em quem poderia ter escrito o texto, essa pessoa teria um espirito adolescente: um tanto ousado - ao mesmo tempo experimentando recursos horas, as referências à internet, artes á́sticaşá, diálo 88 gos do cotidiano, televisão) e lançando a ideia de le todos os livros existentes - mas ainda sem força e maluidade para levar a distâncias maiores o ímpeto de pequenos lampejos (aproveitando o termo que vocês já trouxeram), pequenos eurekas c da - e tampouco problematizam esse vazio. Essa falt de densidade de certa maneira também frustra uma boa ideia de conto.

Justamente por ser tão breve, indo na mesma direçãa das ideias que vocés duas trouxeram, o conto devería ter uma alta carga de trabalho de escrita. Nesse sentido, podemos pensar que o texto poderia ainda ser reescrito, conhecer outras versōes ou continuações - algo que o salvasse da brevidade da nossa memoria. Talvez seja isso o que tentamos fazer: imaginando uma cena de escrita, buscando os espaços em branco que ele abre como eu, a Carol recorrendo a Cortázar de escrita.

\section{Referências bibliográficas}

CORTAZAR, Julio. Alguns aspectos do conto. In: Valise de cronópio. Traduçăo de Davi Arrigucci Júnior. São Paulo Perspectiva, 1974.

FLAUBERT, Gustave. Cartas exemplares (Organização, prefácio e notas de Duda Machado). Rio de Janeiro: Imago, 1993. HOUAISS, Antonio; VILLAR, Mauro de Salles. Grande dicionário Houaiss da língua portuguesa. Rio de Janeiro: Objetiva 2001.

MAUPASSANT, Guy. "Bouvard et Pécuchet", In : FLAUBERT, G. Bouvard et Pécuchet. Éd. Pierre Marc de Biasi. Paris : Librairie Générale de la France/Le Livre de Poche, 1999.

PESSOA, Fernando. Fernando Pessoa: poesia. Rio de janeiro:Livraria Agir Editora, 1970.
Fernando Pessoa, Ferrando Pessoa: poesia, p.8.

Gustave Flaubert, Cartas exemplares

No Le Gaulois, de 6 de abril de 1881, Maupassant declara que Flaubert tinha receio de nao terminar olivro: "Un Iivre parel mange un homme, car nos

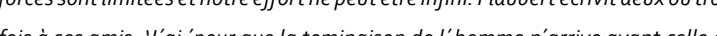
me n'arrive avant celle du

4 Julio Cortázar, "Alguns aspectos do conto", Valise de cronópio, p.153.

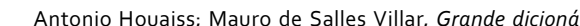

ingua portuguesa,. . 1554-5. 